\title{
NEW FORMS OF NATURAL SCIENCES EDUCATION IN THE CONTEXT OF LOWER SECONDARY EDUCATION IN THE SLOVAK REPUBLIC
}

In our country, there is no debate on road safety education and convenience of the use of computers to carry out this issue. We are aware of the vastness and complexity of the issue and we know that we can and we should explore it in great detail. It is interesting for us to know if pupils achieve better learning results in the first three areas of Niemierko taxonomy (remembering, understanding, specific transfer) when multimedia teaching aid (other than MTA) is used in teaching, and if pupils learn more actively in the classroom, where MTA is used in comparison to teaching applying the traditional teaching methods.

\section{Introduction}

Currently, there are several methods and techniques, according to which it is considered to what extent the work of a teacher was effective in the teaching process. For example, time of active work of pupils in the teaching process is measured. The effectiveness tends to be considered on the basis of knowledge or a change of opinions, attitudes and value orientation. Neither of these methods can be said to be a really optimal indicator of reality, since the results, which are considered, may affect a large number of factors and none of these methods considers them comprehensively [7].

Based on the foregoing, we state that the consideration of the effectiveness of the teaching process currently more or less depends on the ability of the teacher, i. e. to what extent the teacher uses his or her processes, methods and new teaching aids at work, etc.

Although we embarked on implementing the multiannual educational research, experience was more important than the gathered numbers and output to us. The experience was supposed to confirm that MTA is effective and helps pupils when learning the issue of road safety education $[8,9]$.

\section{Search of innovative approaches and forms of teaching in a lower secondary education}

Our long-term interest was, and still is, to teach pupils the elements of RSE. New innovative approaches allow us to use multimedia and computers in teaching. We tried to profit from our skills, knowledge and potential when searching and creating new effective teaching aids, which would fully replace their momentary deficit for the issue, and make the education more effective. Streamlining of teaching is a very difficult and long process and it cannot be solved comprehensively. When creating new multimedia teaching aids, we focused mainly on RSE issues where computers are used as means for teacher's work, but also for pupils- traffic participants. The issues are, in particular, skills to use a bicycle in traffic safely, basis of its maintenance and repair, traffic rules in terms of a cyclist, traffic signs, etc. Handling these applications is the basic "equipment" of today's human society $[8,9]$.

We realize that the use of information technology and computers in the teaching process also brings certain disadvantages and complications, but we believe that when they are used properly, they are indispensable means of humanization of teaching and they significantly contribute to the creativity of pupils. The teacher is the one who must be aware that the computer is a means that can mediate information to the pupils, but emotions and love can be expresses only by the teacher $[5,6]$.

In order to have effective education that would equally develop cognitive and affective area of a personality of the pupil, it is necessary, except for computer technology, to use various methods, contents and forms in teaching. There is no content that could be mediated without methods and there is no mediation without a medium (teaching aid). For these reasons, when we were creating and searching for effective procedures of using the new teaching aid, we tried to use, except for computer technology, synergies of other methods and procedures, particularly in the area of project and problem teaching. The role of MTA is to satisfy the pupil's needs in cognitive but also in affective areas [10].

\footnotetext{
* Jan Stebila

Faculty of Natural Science, Department of Technical and Technology, Matej Bel University, Banska Bystrica, Slovakia, E-mail stebila@fpv.umb.sk
} 


\section{Research of the impact of MTA on development of RSE at Slovak schools}

This chapter aims to present the current results of the research that we gathered in the research of implementation of MTA into teaching. It ought to highlight the merits of using MTA in teaching road safety education. We chose the method of experimental verification for the purposes of this research

\section{Subject of Research}

The research was carried out among pupils of the $2^{\text {nd }}$ level of primary school. The teaching of technical education in selected thematic areas is supported by MTA that we designed for the field of road safety education. There is an optimum support of information and communication technologies.

\section{Aims of Research}

The aim was to verify the success of the use of MTA in real conditions of the selected schools having technical education, where work with computers is also used. We examined the knowledge of the first three levels of educational objectives of Niemierko taxonomy and active learning of pupils.

A natural educational experiment was performed within the research. Teaching was carried out in experimental classrooms (MTA was used in the teaching process) and control classrooms, where the teaching was carried out in a traditional way without using MTA.

We were especially interested in those educational features which have the highest priority in relation to creative-humanistic teaching in the theory.

When dealing with the issue of implementing road safety education of pupils at primary schools, the following objective was set within the educational research: To find out whether it is possible to develop cognitive abilities of a pupil from road safety education for pupils of the $6^{\text {th }}$ year of primary schools with the use of the suggested MTA when teaching technical education.

\section{Research Sample}

The basic set, suitable for our research, were pupils of the $6^{\text {th }}$ year of the $2^{\text {nd }}$ level of primary schools in the Slovak Republic. We can consider the results of the population of pupils of the $6^{\text {th }}$ year in the Slovak Republic to be normally distributed. That is why we can process data as a selection of the normal distribution in the research. In terms of external validity of the research, we performed the sampling selection by a stratified selection. The sample was made of 214 pupils of the $6^{\text {th }}$ year from five primary schools in the Slovak Republic. To be able to objectively determine whether our MTA (independent variable) affects the level of knowledge of road safety education of pupils of the 6th year of primary schools in technical education, we included two groups of respondents in the experiment: the control group and the experimental group. The control and experimental groups were always formed by the entire class. The control group consisted of 107 pupils. 107 pupils were also in the experimental group. Table 1 shows various numbers in the sets of different schools. We purposefully marked all control subgroups as one control group $\mathrm{CON}$ and all the experimental subgroups are identified as one experimental group EXP.

The Overall Summary of the Selection

Table 1 of Pupils into Groups in the Educational Research

\begin{tabular}{|l|c|l|}
\hline $\begin{array}{l}\text { Number of selected classes } \\
\text { of the } 6^{\text {th }} \text { year of the } 2^{\text {nd }} \\
\text { level of primary schools }\end{array}$ & 10 & 214 pupils \\
\hline $\begin{array}{l}\text { Number of groups taking } \\
\text { part in the educational } \\
\text { research }\end{array}$ & 2 & $\begin{array}{l}\text { CONTROL and } \\
\text { EXPERIMENTAL }\end{array}$ \\
\hline $\begin{array}{l}\text { Number of experimental sub- } \\
\text { groups }\end{array}$ & 5 & $\begin{array}{l}\text { a given number of } \\
\text { pupils in every } \\
\text { subgroup }\end{array}$ \\
\hline $\begin{array}{l}\text { Number of control } \\
\text { subgroups }\end{array}$ & 5 & $\begin{array}{l}\text { a given number of } \\
\text { pupils in every } \\
\text { subgroup }\end{array}$ \\
\hline $\begin{array}{l}\text { Experimental group EXP } \\
\text { - experimental subgroup A1 } \\
\text { - experimental subgroup A2 } \\
\text { - experimental subgroup A3 } \\
\text { - experimental subgroup A4 } \\
\text { - experimental subgroup A5 }\end{array}$ & $\begin{array}{l}\text { pupils 22 } \\
\text { pupils 24 } 25 \\
\text { pupils 24 } \\
\text { pupils 12 }\end{array}$ & \\
\hline $\begin{array}{l}\text { Control group CON } \\
\text { - control subgroup B1 } \\
\text { - control subgroup B2 } \\
\text { - control subgroup B3 } \\
\text { - control subgroup B4 } \\
\text { - control subgroup B5 }\end{array}$ & $\begin{array}{l}\mathbf{1 0 7} \\
\text { pupils 22 } \\
\text { pupils 24 } \\
\text { pupils } 25 \\
\text { pupils 24 } \\
\text { pupils 12 }\end{array}$ & \\
\hline
\end{tabular}

\section{Performance of the Experiment}

We started the experiment at primary schools in both groups simultaneously at the beginning of February 2008. Both groups followed the same schedule and content. The only difference in the teaching of both experimental and control groups (EXP, CON) was the application of the verified MTA. This teaching aid was used only in the experimental group, while in the control group the teaching was conducted in a standard way, without the use of this multimedia teaching aid.

During the performance of the experiment, pupils did not know that they are in the experimental group. Thus we were able to ensure the confidentiality against undesirable external influences, and we prevented a formation of intervening variable.

In the way of the above described selection procedure, we developed an assumption to a valid determination of the impact of the experimental operation whereas the intervening variables remained constant during the experiment. The selection procedure, however, could not affect certain effects that could distort research results. Among such effects we included the impact of gender, family ownership of a computer, intelligence, previous experience, etc. Their 
potential impacts on the results of the research are also considered to be constant.

Each pupil was informed that he or she would have to take an obligatory didactic final test, which could not be possible to implement in an alternative day. We believe that due to this requirement, the participation in the final didactic test was of $100 \%$.

The final didactic test was carried out after the thematic unit of road safety education named Machines and Mechanisms. Both groups were tested in their school. All pupils had equal working conditions and the same instructions. The final didactic test for each student consisted of 18 questions. We chose them from the bank of tasks after the agreement with teachers. Pupils had to give or choose the answers. The questions were identical for all pupils. The tests differed only in sequence. Their contents were same. To reduce and minimize cheating, we prepared two versions of the final didactic test. The time limit for the test was 22 minutes. After this time limit, it was not possible to complete the test. Blank questions were evaluated as false, i.e. 0 points. A pupil could get a maximum of 33 points for the whole test, while for each correctly answered question there were 1, 2 or 3 points.

After finishing the test, an anonymous filling in of questionnaires took place. The standardized questionnaire AUS was distributed to pupils. It diagnoses the active learning of pupils during lessons from their answers concerning the teaching of a certain subject. The administration of the questionnaire takes approximately 10 minutes. The total score of the questionnaire corresponds to the process of active learning, which is diagnosed in the questionnaire in five areas:

- PLACE of learning (at home, at school),

- FREQUENCY of situations in which active learning of pupils takes place during a lesson,

- TIME of active learning during a lesson,

- FORM of active learning of pupils during a lesson,

- FEEDBACK on learning.

We considered the inclusion of the standardized questionnaire for a long time, but finally we used it for measuring. However, we think that a more appropriate method for diagnosing this problem would be the method of observation and dialogic methods. The pedagogic experiment took place during lessons in several schools of Slovak towns. For that reason, we could not play the role of the observer.

Filling in the questionnaire took place in the classrooms, which have a classic in-line arrangement of desks. Pupils were sitting in the way they could not cheat.

During the performance of the pedagogic experiment we did not mark any significant effects that could undermine the measured results and the main objective of the research. After the teaching experiment, we collected the obtained data and subjected them to statistical and qualitative analysis.

\section{Statistical Processing and Analysis of the Collected Data}

A standardized questionnaire AUS (Active Learning at School) was used to determine the degree of active learning of pupils. The results of the measurements of the variable ACT were analyzed by the methods of descriptive statistics. The results are comprehensively shown in the following tables and graphs.

The values which are processed in table and graph 1 show the differences in the degree of active learning of pupils during lessons of technical education when MTA was used in the experimental and control groups.

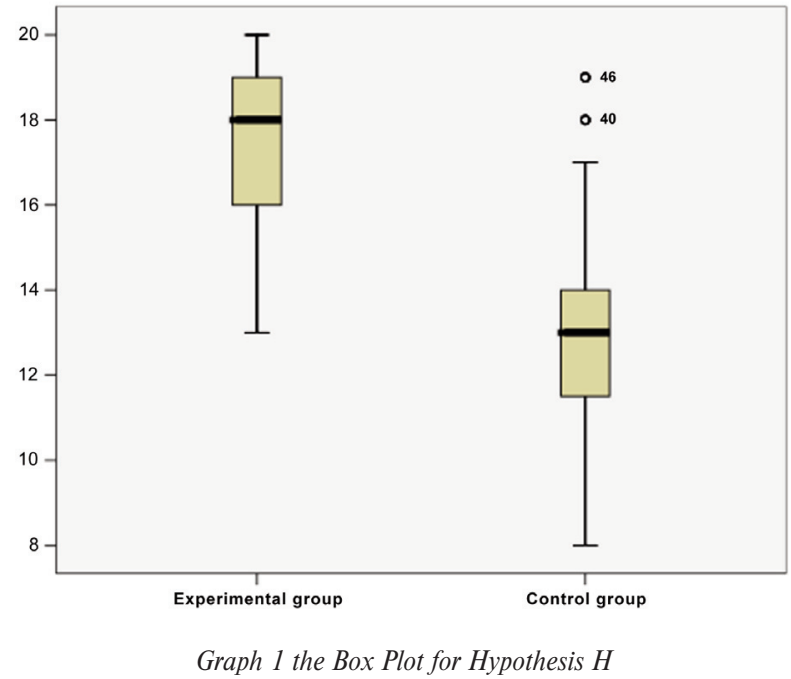

Graph 1 shows that pupils reflected the degree of active learning in a different way. Pupils perceived a very good degree of active learning during lessons in the experimental group. The measured median value shows that the teacher using MTA created favorable conditions for active learning of the pupils. The teacher regularly prepared appropriate learning tasks and activities with the feedback of learning. Pupils were active during the lessons, they learned the subject matter mostly in school and consequently, they did not need to learn at home.

Lower degree of active learning during the lessons was perceived by pupils in the control group. The measured median values indicate that the teacher using methods and teaching aids (other than MTA) did not create very favorable conditions for active learning during the lessons. Pupils could collaborate in groups during the lessons, but the active learning with a feedback of a good quality, due to lack of time, was rare. The activity during the lesson was mostly performed by the teacher. Pupils were rather passive, as observers, during the lessons.

These research results show differences in the degree of learning during lessons of pupils from the experimental and control 

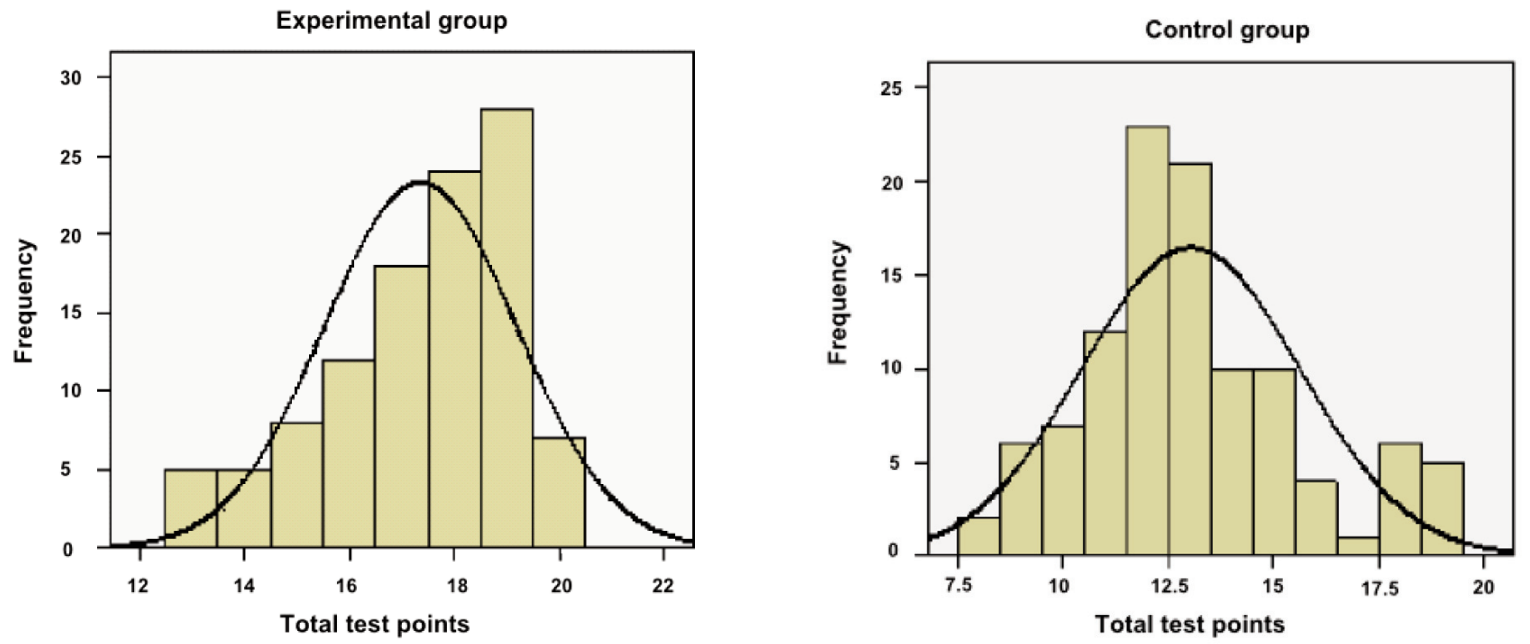

Graph 2 the Histogram of the Frequency of the Variable ACT in Experimental and Control Groups
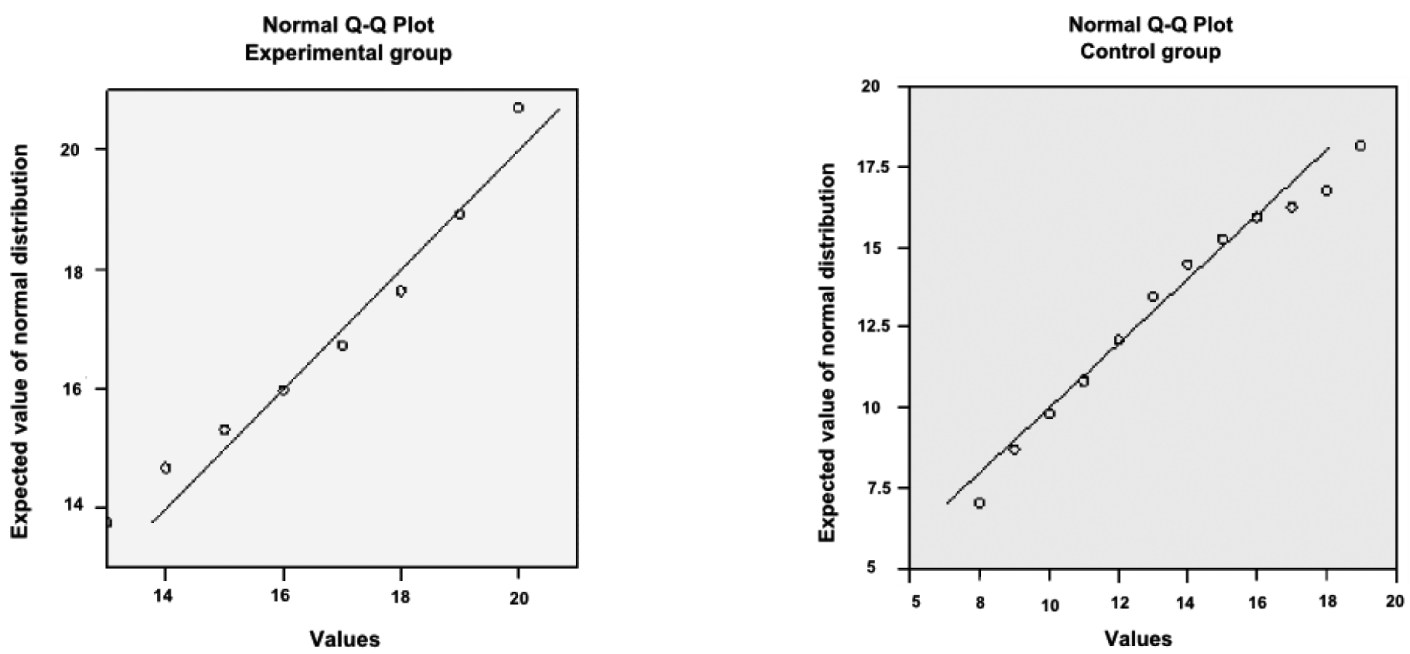

Graph 3 the Approximation of the Distribution of the Variable ACT Frequency to a Normal Distribution

groups. The assumption of the research on the differences in the degree of active learning of pupils in the classroom turned out to be true and confirmed for the sample. The subsequent inductive methods confirmed that assumptions on the differences of the degree of active learning of pupils are applied with the probability of $95 \%$.

Pupils from the control and experimental groups achieved in the research different scores and they were placed in a variety of qualitative intervals within the different scales. In order to generalize the argument as a basic set, we performed an inductive statistical analyze. Based on the analysis of the characteristics of both groups (CON, EXP) we can confirm that it is reasonable to test the hypothesis $\mathrm{H}$ which says that pupils who are taught with MTA will learn during the lessons more actively than pupils who are taught traditionally without using MTA. This means that we will test the hypothesis:
H0: The median value (estimated by the arithmetical average) of experimental and control group is the same.

The implemented Leven F-test unambiguously declares that we reject the hypothesis $\mathrm{H} 0$ of equal scatters $(p=0.017<0.05)$. Because of this, we take into account the results from the bottom line (the output of the statistical system SPSS for two-sided alternative, where $\mathrm{p}$ (T-test) $=0.061$ and $\mathrm{p}$ (T-test) $=0.008$ (for twosided alternative), thus we reject the hypothesis $\mathrm{H} 0$. We summarily show the outputs from the system SPSS of the T-test in the table.

Statistical testing using the T-test confirmed the significance of differences in the performance of experimental group and control group, which is caused by the use of MTA.

The results show that MTA affects the active learning of pupils. The measured value confirmed the test of the hypothesis on the 
The T-test with Two Choices on the Equality of the Median Values for Hypothesis H

Table 4

\begin{tabular}{|c|c|c|c|c|c|c|c|c|c|}
\hline & \multicolumn{2}{|c|}{ Leven F-test } & \multicolumn{7}{|c|}{ T- test on the Equality of the Median Values } \\
\hline & \multirow[t]{2}{*}{$\mathrm{F}$} & \multirow{2}{*}{$\begin{array}{l}\text { P-value of F- } \\
\text { test }\end{array}$} & \multirow[t]{2}{*}{$\mathrm{T}$} & \multirow{2}{*}{ df } & \multirow{2}{*}{$\begin{array}{l}\text { P-value two- } \\
\text { sided alterna- } \\
\text { tive }\end{array}$} & \multirow{2}{*}{$\begin{array}{l}\text { Difference of } \\
\text { Median } \\
\text { Values }\end{array}$} & \multirow{2}{*}{$\begin{array}{l}\text { Standard Error of } \\
\text { the Difference of } \\
\text { Median Values }\end{array}$} & \multicolumn{2}{|c|}{$\begin{array}{l}\text { 95\% konf. Interval } \\
\text { for the Scatter }\end{array}$} \\
\hline & & & & & & & & Down & Upper \\
\hline Equality of scatters & 5.749 & 0.017 & 14.082 & 212 & 0.000 & 4.31776 & 0.3066 & 3.7133 & 4.9222 \\
\hline Inequality of scatters & - & - & 14.082 & 190.596 & 0.000 & 4.31776 & 0.3066 & 3.7129 & 4.9226 \\
\hline
\end{tabular}

significance of differences of the arithmetical averages of the score of the dependent variable ACT (Table 4)

The T-test confirmed that the difference of averages of the total score from the standardized questionnaire AUS (Active Learning at School) of the dependent variable ACT was not random, but it was significant on the level of significance 0.05 .

Based on the facts, we can state that if the teacher taught with the same MTA in the control group as he or she had taught in the experimental group, then pupils would reflect, with greater probability than $95 \%$, the degree of the active learning during lessons in the same way and as pupils from the experimental group.

The research results confirm the assumptions made in the working hypothesis $\mathrm{H}$. We argued that pupils from the experimental group, where MTA was used, would learn more actively during the lessons than pupils from the control group, where teacher did not use the MTA.

The hypothesis was confirmed, and its validity can be generalized to a basic set of pupils who took part in the research.

\section{Evaluation of the Research and Prediction of the Application of MTA in Teaching}

The purpose and the main aim of the pedagogic experiment were to practically verify the success of MTA in conditions of primary schools. We assumed that the use of our multimedia teaching aid in teaching Technical Education on the $2^{\text {nd }}$ level of primary

The Summary of the Verification of the Hypotheses

Table 5

\begin{tabular}{|c|c|c|c|}
\hline Hypothesis & $\begin{array}{c}\text { Method for } \\
\text { Obtaining the } \\
\text { Facts }\end{array}$ & $\begin{array}{c}\text { Validity of the } \\
\text { Hypothesis }\end{array}$ & $\begin{array}{c}\text { Examined } \\
\text { Variable }\end{array}$ \\
\hline H1 & DT - final & Valid & $\begin{array}{c}\text { Performance in } \\
\text { the Cognitive } \\
\text { Area }\end{array}$ \\
\hline H2 & DT - final & Valid & Specific Transfer \\
\hline H3 & DT - final & Valid & Understanding \\
\hline H4 & $\begin{array}{c}\text { Standardized } \\
\text { Questionnaire } \\
\text { AUS }\end{array}$ & Valid & Active Learning \\
\hline
\end{tabular}

schools would significantly affect the level of knowledge of pupils from the issue of road safety education, particularly in terms of performing, remembering, understanding, specific transfer and active learning of pupils.

The validity of the working hypotheses on the level of significance 0.05 is shown in Table 5. We used a non-parametrical test on the compatibility of median values for verifying the main hypothesis.

It is possible to say that from the statistical analyses and conclusions of testing partial hypotheses, the initial hypothesis is confirmed and true on the chosen level of significance 0.05 and in the given conditions. The research on the application of the presented MTA and its methodology on the level of significance 0.05 allows us to state that:

- Pupils who were taught with MTA achieved at the end of the experimental teaching a better performance in the didactic test in the area of specific transfer, understanding and remembering than pupils who were taught traditionally.

- Pupils who were taught with MTA learnt more actively during the lessons than pupils who were taught traditionally.

Teaching with the help of MTA requires an intensive work with modern technologies at the beginning and it is connected with a certain risk that is always present when using computer techniques. Working with the aid gives much more pleasure from teaching and learning. Moreover, the total effectiveness of the learning surpasses traditional forms of education in the subject when using the aid in a right way. MTA designed in this way gives a chance for a greater discussion among pupils in the classroom, teachers and pupils, teachers of technical education and teachers of different subjects.

We are convinced that MTA fully uses the potential of current modern information and telecommunication technologies. The teaching aid integrates current principles of creative and academic education. When we use it in the right way, it can make the process of education significantly simpler and more effective. It helps to satisfy the needs of pupils in the cognitive but also in the affective area that have a key importance in the education of the youth in the long-term point of view.

Information from the experiment but also our experience from using the teaching aid enable us to suggest that MTA has a great chance to become a standard in education with computers in the 
future. The teaching aid of this kind of education has not been elaborated up to now. We hope that this aid will help to standardize the tool in the field of education.

We would like to continue in the pending research in the future. We focus on the possibility of application of MTA in the educational process not only within technical education but also in the subjects where the issue of RSE is included in the content of the subjects at schools of different Slovak regions.

\section{References}

[1] ALESSI, S. M., TROLLTIP, S. R.: Multimedia for Learning, Boston, 2001

[2] AGNEW, P. W.: Multimedia in the Classroom, Massachusetts, Allyn and Bacon, 1996

[3] ENGLAND, E., FINNEY, A.: Managing Multimedia, Project Management for Interactive, Medi, Addison-Wesley, 1999

[4] HILlMAN, D.: Multimedia Technology and Applications, Delmar Publishers, 1998

[5] HOCKICKO, P.: Useful Computer Software for Physical Analysis of Processes, Proc. of the 2009 Information and Communication Technology in Education (ICTE) Annual Conference, 15th-17th September, 2009

[6] McMAHON, K.: Keeping Children Safe in Traffic, Brussels, 2004

[7] KMETOVA, J.: Modernization of Educational Content in Slovak Basic and Secondary Schools, Badania w dydaktyce chemii, Krakow, AP, p. 191-196, 2006

[8] KRISTAK, L.: Teaching Supported by Tasks and Experiments in Physics, 16th Conference of Czech and Slovak Physicists, Hradec Kralove, 2008

[9] NEMEC, M., KRISTAK, L.: Acoustics Experiments, PTEE, Wroclaw, 2009

[10] STEBILA, J.: Results of the Research of Using the Multimedia Teaching Aid under Real Conditions at Primary Schools in SVK, J of Technology and Information Education, Olomouc, Vol. 1, 1/2009, p. 49-54

[11] STEBILA, J.: Incorporating the Problems of the Road Safety Education into the Curriculum of the Technical Education at the Secondary Level of the Elementary Schools, Dissertation thesis, Matej Bel University, Faculty of Natural Sciences, Department of Technology, p. 49-54, 2008

[12] Traffic Safety Education at the Secondary School Level in the EU Countries, Europen Study, Brussels European Road Safety Federation, 1996.

[13] SIHELSKY, B.: How to Create an Educational Project?, Banska Bystrica: Methodical and Pedadogic centre, 2002, ISBN 80-8041441-6. 